\author{
Associate Professor Zheng-Xin Wang, PhD \\ E-mail: zxwang@zufe.edu.cn \\ Zhejiang University of Finance \& Economics \\ Pei-Yi Yao, Master \\ E-mail: 745089115@qq.com \\ Zhejiang University of Finance \& Economics
}

\title{
GREY RELATIONAL ANALYSIS OF ECONOMIC POLICY UNCERTAINTY IN SELECTED EUROPEAN UNION COUNTRIES
}

\begin{abstract}
To estimate the mutual effect of economic policy among European countries, the correlation among economic policy uncertainty (EPU)indices of eight countries in European Union (EU) from March 2003 to January 2017 is studied by using grey relational analysis (GRA). The result shows that under the framework of European economic integration, grey relational degree of EPU of European countries are all above 0.8, which reflects a strong economic policy co-movement of EU countries. The EPU indices of the UK and France with large economic mass are hardly influenced by other countries, which indicate that the economic policy influences of the two countries are larger than those of other countries. Additionally, due to the influence of exiting from the EU, the UK exhibits the lowest and dramatically fluctuating economic policy correlation with the other countries in recent years.

Keywords: European Union; economic policy uncertainty; grey relational analysis.
\end{abstract}

\section{JEL Classification: C63, P16, P52}

\section{Introduction}

Economic policy is one of the most important means for governments to administrate the markets, while economic policy uncertainty (EPU) tends to cause economic fluctuation, which can be divided into political and economic uncertainties. The former is mainly performed as general election of governments while the latter is represented by various fiscal and monetary policies put forth by governments. The general elections do not frequently occur and it is difficult to predict the selection results while the formulation of fiscal and monetary policies of governments is unobservable. As a result of such information asymmetry, it is hard for market decision-making subjects to form a steady prospection, so it is inevitable to have fluctuation in economic activities. Stock \& Watson (2008) regarded EPU as an important factor inducing global financial crisis in 2008 and delaying economic recovery. Therefore, measurement of EPU and its influence on overall economy has attracted wide attention in recent years. Numerous researches concentrate on the influence of EPU on macroeconomic variables of a country 
(Ferrara \& Guérin, 2016) or the mutual influence between both parties of international trades. However, there are only a few researches about the interaction of EPU among multiple countries especially countries within an economic entity (for instance, European Union (EU)). Therefore, the following three problems are worthy studying including the correlation of EPU among multiple countries, dominant countries leading economic policy fluctuation and whether UK's exiting from EU has an influence on economic policy co-movement.

The rest contents are organized as follows: Section 2 shows relevant literature overview; Section 3 displays the methods and data sources; Section 4 gives the analysis and explanation of empirical results; Section 5 displays the conclusions.

\section{Literature overviews}

For economics, the earliest research on uncertainty can be traced back to Keynes' A Treatise on Probability (2013) and Knight's Risk, Uncertainty and Profit (2012), and numerous scholars suggested that uncertainty exerts a negative effect on economic activities. For example, Bernanke (1983) and Stock \& Watson (2012) believed that uncertainty is an important inducement leading to global financial crisis in 2008. However, part of uncertainty is derived from immeasurable political uncertainty (Morikawa, 2013). Although numerous scholars tried to deal with political uncertainty through taking government succession and officer selection into consideration, the institutional changes do not frequently occur and are not suitable for mutual relational analysis among countries. While dealing with the uncertainty influence of different countries or regions, numerous scholars carry out the researches from the perspective of systems. For instance, Pastor \& Veronesi (2012) indicated that uncertainty probably weakens the protection effect of governments on property rights, so the countries with low marketization degrees are more greatly influenced in view of property right protection. Calomiris et al. (2012) discussed the influence of uncertainty on different countries from the perspective of marketization. In the above researches, uncertainty is not directly measured while the influence of uncertainty is measured by using VIX in financial market, for example, Bloom (2009).

Although the method exhibits a favorable effect on financial market, it is probably not suitable for the wider macroeconomic environment. Additionally, in view of different information sources, scholars designed different uncertainty indices. For instance, Scotti(2016) proposed an index reflecting macro-economic uncertainty of economic subjects, and Jurado et al. (2015) put forward an index calculated according to un-predicative variables of macro-economy and finance. Rossi \& Sekhposyan (2015) designed new indexes based on Juardo et al. (2015). However, up to now, the economic and political uncertainty index designed by Baker et al. (2016) based on news report is the most influential.

The grey system theory proposed by Deng (1982)has been applied to deal with the problems in the absence of system information or with incomplete system 
Grey Relational Analysis of Economic Policy Uncertainty in Selected European Union Countries

information. As one of the primary analysis methods of grey system theory, grey relational analysis (GRA) is an effective tool to study the interaction correlation among factors of complex systems, and is also the basis of grey prediction, clustering and decision-making (Andrew, (2011); Liu et al.(2010)). Relevant researches show that GRA can directly evaluate original data instead of making an assumption for original distributions of data, which indicates that GRA is a robust, convenient and intuitional multi-criteria decision-making method (Zhang et al. (2005); Zhai et al. (2009)). Numerous scholars have improved the classical GRA model proposed by Deng (2002). Zhang (1996) introduced grey relation entropy and put forward a new method to calculate correlation degree. Some scholars proposed new grey relational model in view of different distances, such as Euclid relation grade model proposed by Zhao et al. (1998), the range correlation coefficient of differences between the distances of maximum values and sequences proposed by Shi (1995). Liu et al. (2011) put forward grey relational degree based on similarity and nearness.

However, these improved GRA only display the overall correlation degree among variables but fail to provide the correlation coefficients at each observation point. To measure the dynamic change trend of correlation among EPU indices in EU from the time dimension, the classical GRA proposed by Deng (2002) is applied in this study.

\section{Data and methods}

\subsection{Data}

The EPU index applied in the study is taken from the indices constructed based on news report frequency by Baker et al. (2016) and the specific data are collected from http://www.policyuncertainty.com/index.html. For European countries, the specific method to construct the index is displayed as follows: newspapers from two press offices are taken in each country and the news numbers with the following specific words are counted. The specific words include: (1) uncertain or uncertainty, (2) economic or economy, and (3) one or multiple words related to politics. Subsequently, each sequence is normalized and monthly EPU indices of various countries are obtained. Considering GRA requires that data sequences have the same length, EPU data of eight European countries from March 2003 to January 2017 are chosen including Sweden, Germany, Italy, UK, France, Spain, Netherlands and Ireland. Fig 1 displays the sequence of EPU indices of the eight countries. 


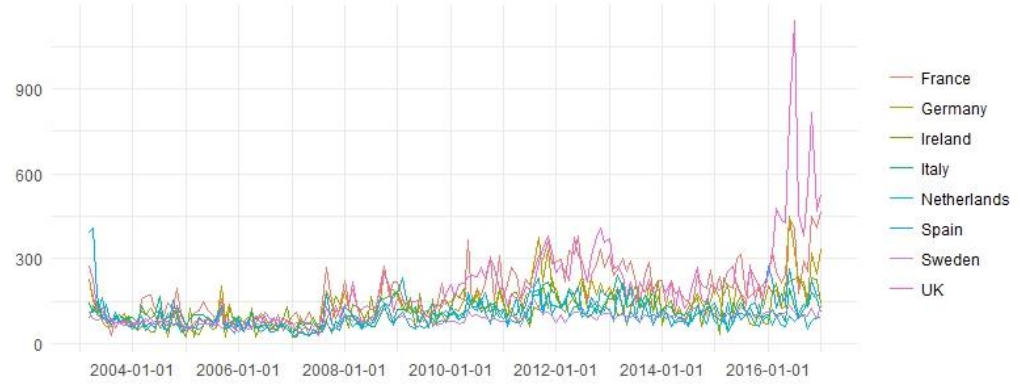

Figure 1. EPU indices of the eight countries

It can be seen from Fig 1 that these countries exhibited stable EPU before 2008 but EPU fluctuated afterwards. Moreover, it can be seen that the UK, France and Germany have large absolute figures, which indicates that EPU of the three countries is larger than that of other countries. Additionally, EPU index of the UK has two peaks, which is caused by the exiting from EU in July 2016.

Table 1. EPU descriptive statistics of various countries

\begin{tabular}{|c|cccccccc|}
\hline & Sweden & Germany & Italy & UK & France & Spain & Netherlands & Ireland \\
\cline { 2 - 6 } Observation & 167 & 167 & 167 & 167 & 167 & 167 & 167 & 167 \\
Minimum & 53.73 & 28.43 & 31.98 & 30.47 & 30.62 & 23.32 & 27.21 & 22.97 \\
Mean & 90.14 & 134.19 & 109.74 & 190.71 & 183.46 & 108.10 & 97.60 & 120.51 \\
Median & 89.05 & 122.00 & 104.18 & 157.73 & 170.78 & 97.27 & 91.63 & 120.57 \\
Maximum & 156.73 & 451.42 & 241.02 & 1141.80 & 462.97 & 407.42 & 233.73 & 235.70 \\
Skewness & 0.45 & 1.41 & 0.69 & 2.79 & 0.68 & 2.03 & 0.97 & 0.20 \\
Kurtosis & 0.01 & 3.15 & 0.43 & 12.29 & 0.04 & 7.37 & 0.66 & -0.65 \\
Jarque-Bera & 5.77 & 128.36 & 14.86 & 1303.62 & 13.27 & 508.31 & 30.16 & 3.90 \\
(Probability) & 0.056 & 0.000 & 0.000 & 0.000 & 0.001 & 0.000 & 0.000 & 0.142 \\
\hline
\end{tabular}

Table 1 shows descriptive statistics of EPU indices of various countries. It can be seen from the table that Sweden and the UK exhibit the lowest and the largest fluctuation ranges of EPU, respectively while the latter is followed by France, Germany and Spain in terms of fluctuation range. Jarque-Bera test of sequence normality shows that at a significance level of 5\%, the sequences of other countries significantly reject the null hypotheses except for Sweden and Ireland, which indicates that EPU index is not derived from normal populations. 
Grey Relational Analysis of Economic Policy Uncertainty in Selected European Union Countries

\subsection{Grey relational model}

Grey relational analysis is mainly applied to calculate the correlation degree between behavior and relevant factor sequences of systems and this kind of models is represented by the grey relational model (Deng, 2002). Moreover, based on four axioms of grey relation, the model is used to measure the similarity of system change trend according to the distances between corresponding points of sequences. Different from the common statistical analysis such as regression analysis and variance analysis, GRA does not require large sample size data and there is no hypothesis of prior distribution for data. For the system behavior sequence:

$$
X_{0}=\left(x_{0}(1), x_{0}(2), \mathrm{L}, x_{0}(n)\right)
$$

As well as relevant factor sequence:

$$
X_{i}=\left(x_{i}(1), x_{i}(2), \mathrm{L}, x_{i}(n)\right) i=1,2, \mathrm{~L}, m
$$

Given $\xi \in(0,1)$, assuming that:

$$
\begin{gathered}
\gamma\left(x_{0}(k), x_{i}(k)\right)=\frac{\min _{i} \min _{k}\left|x_{0}(k)-x_{i}(k)\right|+\xi \max _{i} \min _{k}\left|x_{0}(k)-x_{i}(k)\right|}{\left|x_{0}(k)-x_{i}(k)\right|+\xi \max _{i} \min _{k}\left|x_{0}(k)-x_{i}(k)\right|} \\
\gamma\left(X_{0}, X_{i}\right)=\frac{1}{n} \sum_{k=1}^{n} \gamma\left(x_{0}(k), x_{i}(k)\right)
\end{gathered}
$$

Where, ${ }^{\xi}$ refers to identification coefficient, which generally values 0.5 while $\gamma\left(X_{0}, X_{i}\right)$ represents grey relational degree between $\mathbf{X}_{0}$ and $\mathbf{X}_{\mathrm{i}}$. follows:

The specific steps to calculate the grey relational degrees are shown as

Step1: Dimensionless processing is conducted on each sequence using commonly used methods including initial value and mean value methods.

Considering that the all sequences of the EPU index have the same dimensions, it is unnecessary to carry out the processing.

Step 2: The difference sequence is solved, which is displayed as follows:

$$
\Delta_{i}(k)=\left|x_{0}(k)-x_{i}(k)\right|, \Delta_{i}=\left(\Delta_{i}(1), \Delta_{i}(2), \mathrm{L}, \Delta_{i}(n)\right), i=1,2, \mathrm{~L}, m
$$
as follows:

Step 3: Maximal and minimal differences of both ends are solved, recorded

$$
M=\max _{i} \max _{k} \Delta_{i}(k), m=\min _{i} \min _{k} \Delta_{i}(k)
$$

Step 4:Calculation of correlation coefficient 


$$
\gamma_{0 i}(k)=\frac{m+\xi M}{\Delta_{i}(k)+\xi M}, \xi \in(0,1), \quad k=1,2, \mathrm{~L}, m
$$

Where, $\xi$ refers to identification coefficient, which generally values 0.5 .

Step 5: Calculation of correlation degree;

$$
\gamma_{0 i}=\frac{1}{n} \sum_{k=1}^{n} \gamma_{0 i}(k), i=1,2, \mathrm{~L}, m
$$

\subsection{Preference analysis}

After calculating the grey relational degree of the system, grey relational matrix can be further calculated so as to analyze the advantages of various factors. The grey relation matrix is defined as follows:

Suppose that $Y_{1}, Y_{2}, \mathrm{~L}, Y_{S}$ and $X_{1}, X_{2}, \mathrm{~L}, X_{m}$ are separately system feature behavior and relevant factor sequences. Moreover, $Y_{i}$ has the same length as $X_{j}$ and $\gamma_{i j}(i=1,2, \mathrm{~L}, s ; j=1,2, \mathrm{~L}, m)$ represents the grey relational degree between $Y_{i}$ and $X_{j}$. Thus,

$$
\Gamma=\left(\gamma_{i j}\right)=\left[\begin{array}{cccc}
\gamma_{11} & \gamma_{12} & \mathrm{~L} & \gamma_{1 m} \\
\gamma_{21} & \gamma_{22} & \mathrm{~L} & \gamma_{2 m} \\
\mathrm{M} & \mathrm{M} & & \mathrm{M} \\
\gamma_{s 1} & \gamma_{s 2} & \mathrm{~L} & \gamma_{s m}
\end{array}\right]
$$

is the grey relational matrix.

If there exist $k$ and $i \in\{1,2, \ldots, \mathrm{s}\}$ satisfying

$$
\gamma_{k j} \geq \gamma_{i j}
$$

for $j=1,2, \ldots, m$, then we say that the system's characteristic $\mathrm{Y}_{\mathrm{k}}$ is more favorable than the system's characteristic $\mathrm{Y}_{\mathrm{i}}$, denote as $\mathrm{Y}_{k}>\mathrm{Y}_{i}$. If for any $i=1,2, \ldots, s$, with $i \neq k$, we always have $Y_{k}>Y_{i}$, then $Y_{k}$ is said to be the most favorable characteristic.

If there exist $l$ and $j \in\{1,2, \ldots, m\}$ satisfying

$$
\gamma_{i l} \geq \gamma_{i j}
$$

for $j=1,2, \ldots, m$, then the factor $\mathrm{X}_{l}$ is more favorable than the factor $\mathrm{X}_{j}$, denote as $\mathrm{X}_{l}>\mathrm{X}_{j}$. If for any $j=1,2, \ldots, m$, with $j \neq l$, we always have $\mathrm{X}_{l}>\mathrm{X}_{j}$, then $\mathrm{X}_{l}$ is called the most favorable factor.

If there exist $k, i \in\{1,2, \ldots, s\}$ satisfying 
Grey Relational Analysis of Economic Policy Uncertainty in Selected European Union Countries

$$
\sum_{j}^{m} \gamma_{k j} \geq \sum_{j}^{m} \gamma_{i j}
$$

then the system's characteristic $\mathrm{Y}_{k}$ is said to be more quasi-favorable than the characteristic $\mathrm{Y}_{i}$, denoted $\mathrm{Y}_{k} \geqslant \mathrm{Y}_{i}$.

If there exist $l, \mathrm{j} \in\{1,2, \ldots, \mathrm{m}\}$ satisfying

$$
\sum_{i}^{s} \gamma_{i l} \geq \sum_{i}^{s} \gamma_{i j}
$$

then the factor $\mathrm{X}_{l}$ is said to be more quasi-favorable than the factor $\mathrm{X}_{\mathrm{j}}$, denoted $\mathrm{X}_{l} \succcurlyeq \mathrm{X}_{j}$.

\section{Empirical results}

\subsection{Relational order of EPU indices of the eight countries in EU}

By employing the EPU index proposed by Baker et al. (2016), the economic and political uncertainty degrees of the eight countries in EU from March 2003 to January 2017 are measured. Table 2 displays the grey relational matrix calculated by using the data.

It can be seen from Table 2 that the grey relational degrees of the eight countries exhibit dissymmetry, which indicates that there is the influence of system environment. Moreover, the values are all larger than 0.8, which implies that EPU indices of the eight countries exhibit a significant grey relational effect.

Based on the grey relational matrix, preference analysis of economic policy influence of the eight countries is further conducted. The result is shown in Table 3 and Table 4.

The following relational order can be obtained based on Table 3 when EPU index as system character.

$U K<$ France $<$ Sweden $<$ Ireland $<$ Netherlands $<$ Spain $<$ Germany $<$ Italy

The following relational order can be obtained based on Table 4 when EPU index as factor.

France $\mathrm{p} U K \mathrm{p}$ Gemany $\mathrm{p}$ Ireland $\mathrm{p}$ Spain $\mathrm{p}$ Sweden $\mathrm{p}$ Netherlands $\mathrm{p}$ Italy

It can be seen that France and the UK have the lowest order of dominance whenever their EPU index as system character or factor. It indicates that when economic and political uncertainties of those countries are interacted with those of other countries, the influence of other countries is lower than that of factors of their 
own. This further suggests that EPU of France and the UK is mainly dominated by their own countries.

Table 2. Grey relational matrix of EPU indices of the eight European countries

\begin{tabular}{|l|llllllll|}
\hline & Sweden & Germany & Italy & UK & France & Spain & Netherlands & Ireland \\
\hline Sweden & 1.0000 & 0.9147 & 0.9480 & 0.8550 & 0.8572 & 0.9428 & 0.9496 & 0.9221 \\
Germany & 0.8966 & 1.0000 & 0.9077 & 0.8714 & 0.8845 & 0.9099 & 0.9003 & 0.9057 \\
Italy & 0.9471 & 0.9230 & 1.0000 & 0.8697 & 0.8765 & 0.9407 & 0.9458 & 0.9332 \\
UK & 0.8583 & 0.8951 & 0.8744 & 1.0000 & 0.9134 & 0.8714 & 0.8668 & 0.8822 \\
France & 0.8109 & 0.8740 & 0.8413 & 0.8831 & 1.0000 & 0.8284 & 0.8224 & 0.8465 \\
Spain & 0.9399 & 0.9223 & 0.9387 & 0.8623 & 0.8621 & 1.0000 & 0.9322 & 0.9146 \\
Netherlands & 0.9511 & 0.9200 & 0.9482 & 0.8668 & 0.8663 & 0.9372 & 1.0000 & 0.9239 \\
Ireland & 0.9135 & 0.9141 & 0.9269 & 0.8679 & 0.8706 & 0.9098 & 0.9132 & 1.0000 \\
\hline
\end{tabular}

Note: first column as system character and others as factors

Table 3. Order of dominance of the eight countries as system character

\begin{tabular}{|cccccccc|}
\hline Sweden Germany & Italy & \multicolumn{4}{l|}{ UK } & \multicolumn{4}{l|}{ France Spain Netherlands Ireland } \\
\hline 7.32 & 7.36 & 7.39 & 7.08 & 7.13 & 7.34 & 7.33 & 7.33 \\
& & & & & & \\
\hline
\end{tabular}

Table 4. Order of dominance of the eight countries as factors

\begin{tabular}{|cccccccc|}
\hline Sweden Germany & Italy & UK & \multicolumn{3}{l|}{ France } & Spain Netherlands Ireland \\
\hline 7.39 & 7.28 & 7.44 & 7.16 & 6.91 & 7.37 & 7.41 & 7.32 \\
& & & & & & & \\
\hline
\end{tabular}

4.2 Point relational coefficients of EPU indices of the eight countries

To explore the dynamic change trend of EPU indices of the eight countries, point relational coefficients of EPU of the eight countries are analyzed.

Figures 2 9 display the sequences of grey point relational coefficients by separately taking Sweden, Germany, Italy, UK, France, Spain, Netherlands and Ireland as system behavior sequences. 
Grey Relational Analysis of Economic Policy Uncertainty in Selected European Union Countries

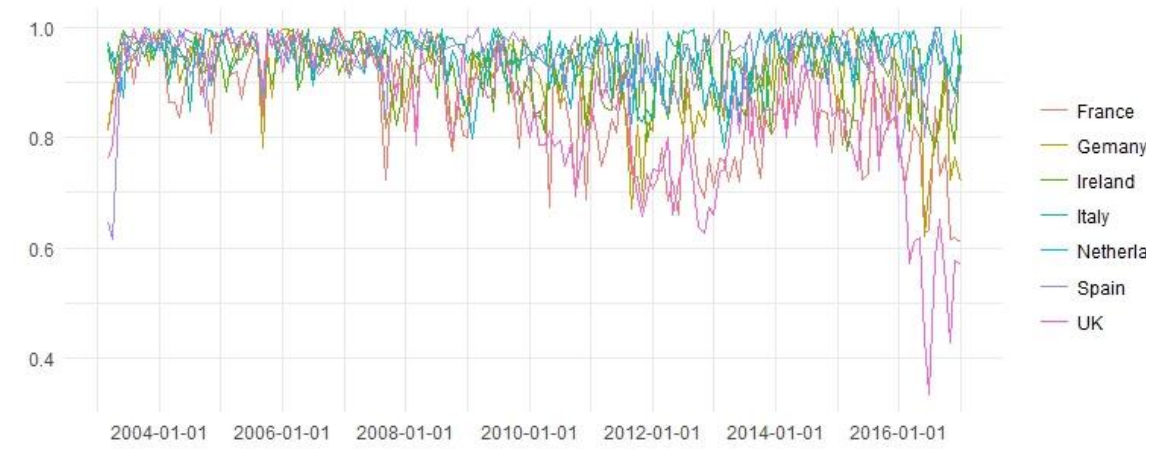

Figure 2.Taking Sweden as a system behavior sequence

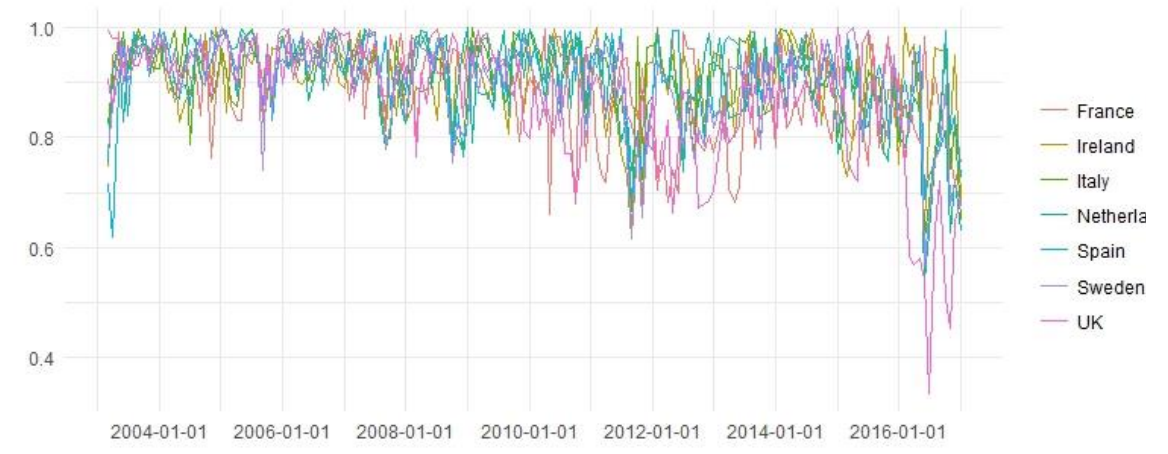

Figure 3. Taking Germany as a system behavior sequence 


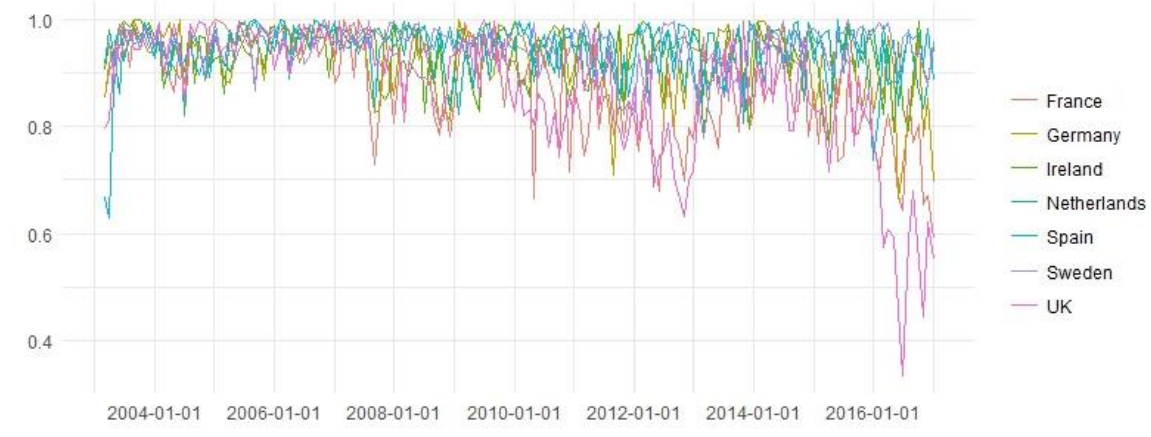

Figure 4. Taking Italy as a system behavior sequence

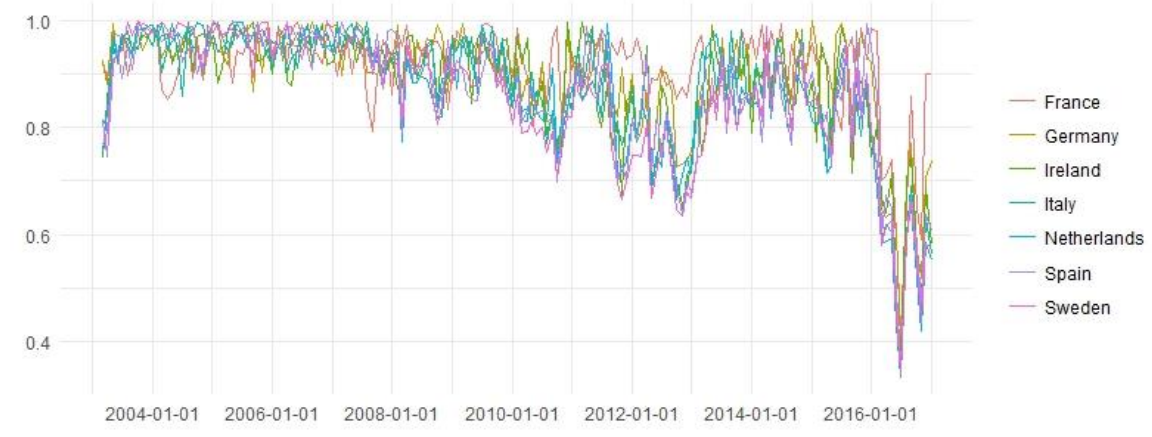

Figure 5. Taking the UK as a system behavior sequence

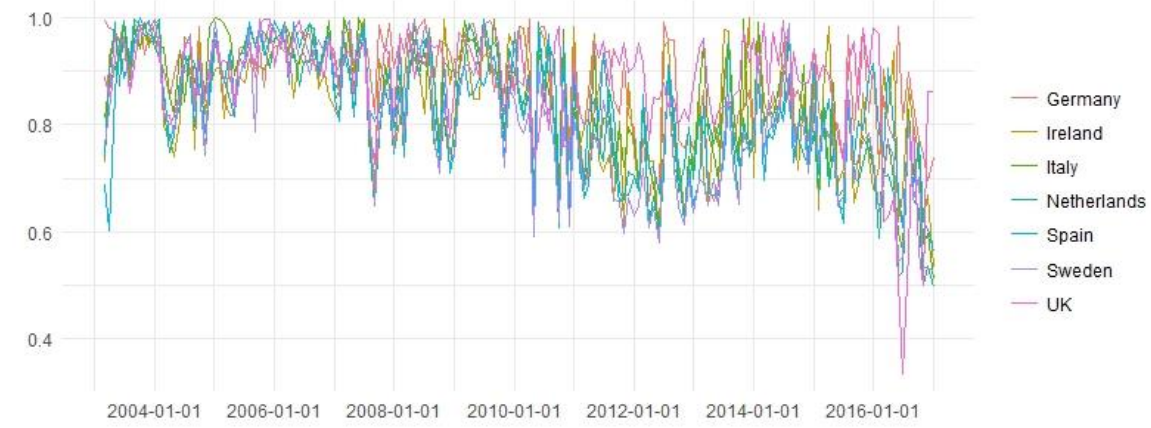

Figure 6. Taking France as a system behavior sequence 
Grey Relational Analysis of Economic Policy Uncertainty in Selected European Union Countries

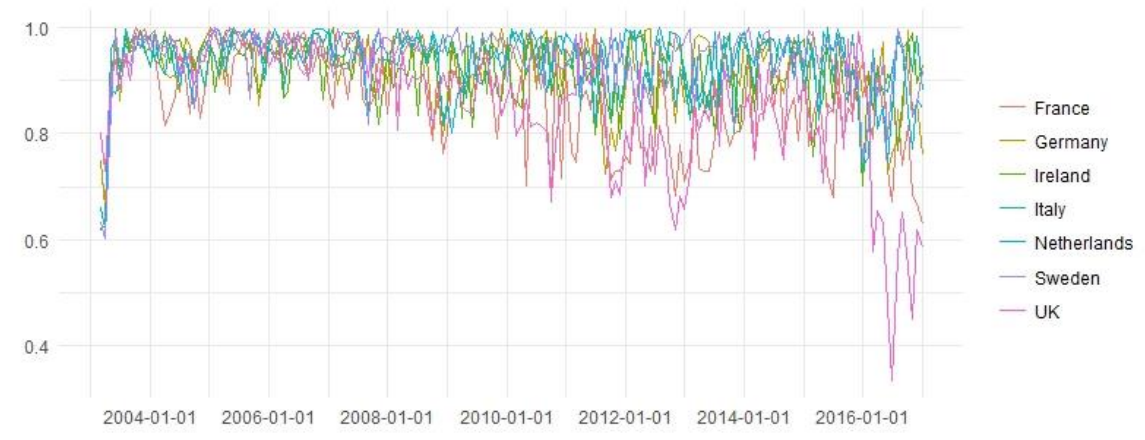

Figure 7. Taking Spain as a system behavior sequence

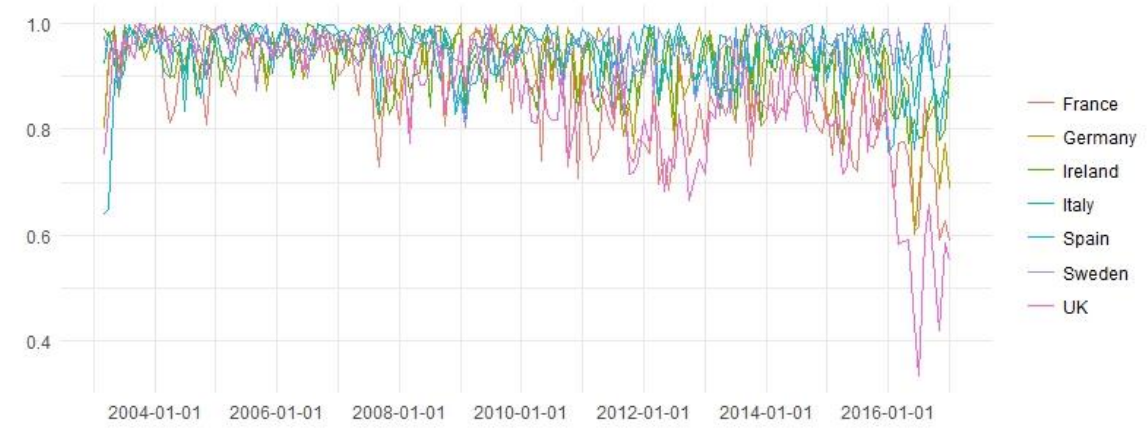

Figure 8. Taking Netherlands as a system behavior sequence

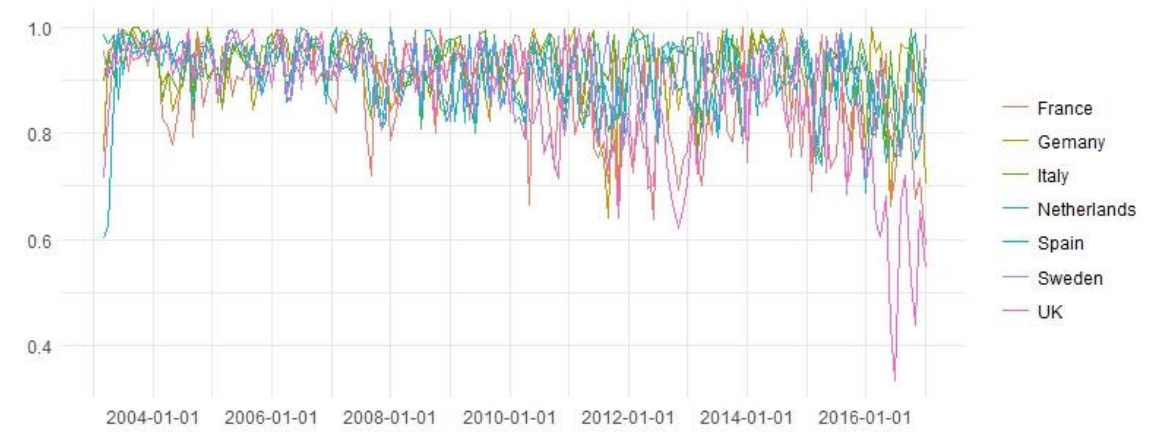

Figure 9. Taking Ireland as a system behavior sequence 
It can be seen from Figure 2 that Sweden has the largest point relational coefficients with Netherlands and Italy while low and greatly fluctuating grey relational degrees with the UK, France and Germany. It indicates that the correlation of EPU of Sweden with the UK and Germany is not dominated by its own factors.

It can be seen from Figure 3 that the point relational coefficients of the UK and France with Germany exhibit a more significant difference compared with those of the other countries. This is illustrated by a lower grey relational degree compared with those of the other countries. It indicates that the EPU of Germany with the UK and France exhibits complex correlation, which is not controlled by any country.

It can be seen from Figure 4 that Italy shows the largest point relational coefficient with Sweden and Netherlands while low grey relational degrees with the UK, France and Germany and the fluctuation degree increases. It indicates that the correlation of EPU of Italy with the UK and Germany is not dominated by its own factors.

France shows the largest grey relational degree with the UK, followed by Germany and Ireland. It can be seen from Fig 5 that the point relational coefficients of the other countries are highly similar to that of the UK, which indicates that EPU of the UK is mainly controlled by its own factors. Moreover, the grey relational degree between the UK and the other countries has been dramatically declined since 2016 and the peak valley occurred in July 2016, which shows that UK's exiting from EU exerted a significant influence on its EPU.

Germany and the UK exhibit the largest grey relational degrees with France. It can be seen from Fig 6 that the point relational coefficients between France and the other countries have a significant fluctuation. Moreover, they have been increasingly decreased in recent years and all curves exhibit a highly similar trend. These show that the correlation between EPU of France and the other countries (except for the UK) is dominated by the own factors of France and economic and political uncertainties of France strengthen. Additionally, the correlation curve between the UK and France is different from those between the other countries and France, and the former has the largest fluctuation. It implies that the influence relation between the UK and France is not controlled by any country alone.

Sweden and Italy have the largest grey relational degree with Spain. It can be seen from Fig 7 that Spain has the largest point relational degree with Italy and Sweden in a long term. However, Spain shows a low grey relational degree with the UK, France and Germany and the fluctuation degree rises. It indicates that the correlation of EPU of Spain with the UK, France and Germany is not controlled by its own factors.

Sweden, Italy and Spain exhibit the largest grey relational degree with Netherlands. It can be seen from Fig 8 that Netherlands exhibits the largest grey relational degree with Sweden, Spain and Italy while low grey relational degrees 
Grey Relational Analysis of Economic Policy Uncertainty in Selected European Union Countries

with the UK and Germany and the fluctuation degree increases in recent years. It shows that the correlation of EPU of Netherlands with the UK and Germany is not dominated by its own factors.

Italy shows the largest grey relational degree with Ireland. It can be seen from Fig 9 that Ireland has the largest grey relational degree with Netherlands and Italy while low grey relational degrees with the UK, Germany and France with increasingly evident fluctuations in recent years. It indicates that the correlation of EPU of Ireland with the UK, France and Germany is not controlled by factors of Ireland.

It can be seen from Figures 2 9 that EPU degrees of the eight countries show a large grey relational degree with stability for a long time, which suggests that there is a large integration degree among the eight European countries. However, by observing the grey relational matrix and conducting advantage analysis, it can be seen that countries with large economic mass (such as the UK, France and Germany) exhibit a relatively low grey relational degree with the other countries. Moreover, the sequence charts of grey relational show that the three curves at the bottom of each figure separately represent the UK, Germany and France and their fluctuation degrees have constantly risen in recent two years. It indicates that EPUs of the three countries are mainly dominated by factors of their own countries. Moreover, there is an increasingly rising trend.

Additionally, it can be seen that grey relational degree between the UK and other countries has significantly decreased since 2016 and there are two peaks on the right, corresponding to July and November 2016. As a matter of fact, UK's EU referendum was held on June 23, 2016 and the new Prime Minister Theresa Mary May declared the schedule of exiting from EU in October. This series of events greatly improve economic and political uncertainties of the UK, illustrated by the decrease of the grey relational degree between the UK and the other countries.

\section{Conclusions}

By analyzing the results of descriptive statistics, it can be seen that economic and political uncertainties of various countries constantly rise and there is a similar fluctuation degree. However, economic and political uncertainties of the UK have dramatically fluctuated in recent years and the peaks occurred after holding the EU referendum.

The result of GRA suggests that European countries exhibit a high grey relational degree on the whole. This indicates that there is a close influence relationship in economies and politics among European countries. However, by combining the sequence charts of grey relational degrees and the result of advantage analysis, it can be seen that the grey relational degrees of the UK, France and Germany with the other countries are lower than the correlation degrees 
among the other five countries. This shows that EPUs of the UK, France and Germany are mainly influenced by the factors of their own countries.

The influence of EU referendum of the UK is reflected in all sequence charts of grey relational, and can be manifested as the dramatic decrease of grey relational degree between the UK and the other countries. GRA can be used to evaluate mutual correlations of economies and policies of different countries under uncertain conditions as well as favorably reflect the influence of exterior Black swan events.

\section{REFERENCES}

[1] Stock, J. H. \& Watson, M. W. (2012), Disentangling the Channels of the 2007-2009 Recession (No. w18094); National Bureau of Economic Research;

[2] Ferrara, L. \& Guérin, P. (2016), What Are the Macroeconomic Effects of High-Frequency Uncertainty Shocks (No. 2016-25);Bank of Canada Staff Working Paper;

[3] Keynes, J. M. (2013), A Treatise on Probability;Courier Corporation;

[4] Knight, F. H. (2012), Risk, Uncertainty and Profit;Courier Corporation;

[5] Bernanke, B. S. (1983), Irreversibility, Uncertainty, and Cyclical Investment; The Quarterly Journal of Economics, 98(1), 85-106;

[6] Morikawa, M. (2013), What Type of Policy Uncertainty Matters for Business? Research Institute of Economy, Trade and Industry (RIETI);

[7] Pastor, L. \& Veronesi, P. (2012), Uncertainty about Government Policy and Stock Prices; The Journal of Finance, 67(4), 1219-1264;

[8] Calomiris, C. W., Love, I. \&Pería, M. S. M. (2012), Stock Returns' Sensitivities to Crisis Shocks: Evidence from Developed and Emerging Markets; Journal of International Money and Finance, 31(4), 743-765;

[9] Bloom, N. (2009), The Impact of Uncertainty Shocks; Econometrica, 77(3), 623-685;

[10] Scotti, C. (2016), Surprise and Uncertainty Indexes: Real-time Aggregation of Real-activity Macro-surprises; Journal of Monetary Economics, 82, 1-19;

[11] Jurado, K., Ludvigson, S. C. \& Ng, S. (2015), Measuring Uncertainty; The American Economic Review, 105(3), 1177-1216;

[12] Rossi, B. \& Sekhposyan, T. (2015), Macroeconomic Uncertainty Indices Based on Nowcast and Forecast Error Distributions; The American Economic Review, 105(5), 650-655;

[13] Baker, S. R., Bloom, N. \& Davis, S. J. (2016), Measuring Economic Policy Uncertainty; The Quarterly Journal of Economics, 131(4), 1593-1636;

[14] Deng, J.L. (1982), Control Problems of Grey Systems; Systems \& Control Letters, 1(5), 288-294;

[15] Deng, J.L. (2002), The Elements on Grey Theory; Huazhong University of Science and Technology Publisher; 
Grey Relational Analysis of Economic Policy Uncertainty in Selected European Union Countries

[16] Andrew, A. M. (2011), Why the World is Grey; Grey Systems: Theory and Application, 1(2), 112-116;

[17] Liu Sifeng, Dang Yaoguo, Fang Zhigeng, et al. (2010), Grey System Theory and Its Application. 6th ed; Beijing: Science Press, 2010: 169-175;

[18] Zhang, J. Wu, D. \& Olson, D. L. (2005), The Method of Grey Related Analysis to Multiple Attribute Decision Making Problems with Interval Numbers; Mathematical and computer modelling, 42(9-10), 991-998;

[19] Zhai, L. Y., Khoo, L. P. \& Zhong, Z. W. (2009), Design Concept Evaluation in Product Development Using Rough Sets and Grey Relation Analysis; Expert Systems with Applications, 36(3), 7072-7079;

[20] Zhang, Q. S., Guo, X. J. \& Deng, J. L. (1996), Grey Relation Entropy Method of Grey Relation Analysis; Systems Engineering Theory \& Practice, 8(8), 7-11;

[21] Zhao, Y. L., Wei, S. Y. \& Mei, Z. X. (1998), Grey Euclid Relation Grade; Journal of Guan Xi University, 23(1), 10-13;

[22] Baozheng, S. (1995), Presentation of Range Incidence Quantity; Journal of the University of Petroleum, China;

[23] Liu, S. F., Xie, N. M. \& Forrest, J. (2011), Novel Models of Grey Relational Analysis Based on Visual Angle of Similarity and Nearness; Grey Systems: Theory and Application, 1(1), 8-18. 